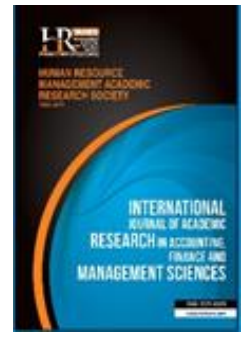

International Journal of Academic Research in Accounting, Finance and Management Sciences

Vol. 10, No.2, April 2020, pp. 200-210

E-ISSN: 2225-8329, P-ISSN: 2308-0337

(c) 2020 HRMARS

www.hrmars.com

To cite this article: Khalfan, I., Said, S., Jamaluddin, Z., Widyarto, S. (2020). Conceptual Framework on Quality Management Practices and Operational Performance for ISO 9001 Certified Construction Industries, International Journal of Academic Research in Accounting, Finance and Management Sciences 10 (2):200-210

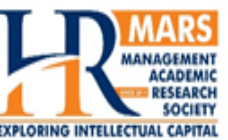

\title{
Conceptual Framework on Quality Management Practices and Operational Performance for ISO 9001 Certified Construction Industries
}

\author{
Issa Khalfan ${ }^{1}$, Sulaiman Said ${ }^{2}$, Zaharuzaman Jamaluddin ${ }^{3}$, Setyawan Widyarto ${ }^{4}$ \\ ${ }^{1,2,3}$ Faculty of Business and Accountancy, Universiti Selangor, Malaysia, ${ }^{1}$ E-mail: alsalmiworld@hotmail.com, \\ ${ }^{2} E$-mail:alsalmiworld@hotmail.com, ${ }^{3} E$-mal: zaharuzaman@unisel.edu.my \\ ${ }^{4}$ Centre for Graduate Studies, Universiti Selangor, Malaysia, ${ }^{4} E$-mail: swidyarto@unisel.edu.my
}

\begin{abstract}
Quality Management Practices are vital approach towards improving operational performance. The main objective of the study is to analyze the effect of Quality Management (QM) practices on Operational Performance (OP) with the help of leadership and Quality Culture (QC) in construction industries particularly in 9001 accredited construction industries. This is because of lack of study on QM practice, Operational Performance (OP) in the area of construction industries. Moreover, the 9001 accredited construction industry has had more opportunities to implement the quality management practices, which attributes to improve the quality of the overall stages of the project. Furthermore, this study will analyze the important of QC in the construction field. Normally, the aims of the construction industries are to create stability among cost, time and quality. QM is a key indicator of the reliability and durability of constructed project. An appropriate level of quality could be determined during an entire project life cycle, which includes initiation, planning, execution, monitoring, and close phases until the operation and maintenance phase is completed. Generally, a project with high quality work arrangement is more likely to have a smoother take over to the operation and maintenance phase. The literature review shows that the quality management practice can be effectively triggred in operational performance. Accordingly, this research will implement the QC and leadership to be as a key influencer to support the QM practices in construction industries in terms of operational performance. This study reviews various literatures to propose a conceptual framework which compile the four main variables (QM practices, leadership, QC and $O P$ ) to analyze the relation among them and to provide the proper framework that suites construction field. Eventually, the conclusion has been introduced which the covered practice finding to underpin for construction industries. Educationally, this study contributes, to improve the knowledge of people and to introduce the important of those variables in the project. Practically, this study provides an impulse for industrial practitioners to understand key roles of variables in construction industries in order to improve the $O P$, by providing empirical evidence.
\end{abstract}

Key words

Construction Industries, Leadership, Quality Culture, Operational Performance, Quality Management Practices

Received: 17 Jul $2020 \quad$ C The Authors 2020

Revised: 09 Jul 2020 Published by Human Resource Management Academic Research Society (www.hrmars.com)

Accepted: $22 \mathrm{Jul} 2020$ This article is published under the Creative Commons Attribution (CC BY 4.0) license. Anyone may reproduce, distribute, translate and create derivative works of this article (for both commercial and non-commercial purposes), subject to full attribution to the original publication and authors. The full terms of this license may be seen at: http://creativecommons.org/licences/by/4.0/legalcode

\section{Introduction}

There are several definitions of quality from researchers. The objective of the section is to provide its own definition of quality, which is related to the present study. During the previous researches related to the quality, the definitions of quality varied from one researcher to other. The definition of quality is reflected and depended on the nature of study. For instance, according to the Reeves et al. (1994) defined the quality as anticipation of meeting the need of customer, provide the important tool for priority and 
excellence, conformance to characteristic. Here are some of the definitions of quality according to the experts:

- Cosroby (1979) defined the quality as certain condition and requirement that need to company's won quality and the quality is seen from inner view not only outer view.

- Feigenbaum (1986), Juran (1982), and Deming (1986) they insist that the quality of anything can be noticed from the customer perception and from outer customer.

- According to Juran (1995), the quality defined as the worthy performance of the product and also the value of the customer satisfaction.

- Based on the previous researchers, e.g. Juran et al. (1989), Deming (1986), and Feigenbaum (1986), they noticed the quality definition have used for several organizations such as small and medium enterprises and manufacturer.

Furthermore, Feigenbaum (1986) and Juran (1988) identified the quality as an essential element, in order to achieve the organizational performance and also the element is either product or service which, at the end fulfils the need of the user. There are several divisions that can positively influence on participation and integration of the product quality delivery, for example marketing, accounting, engineering, design, production and manufacturing department. Therefore, quality is a viable element of the entire organization and the main aim of the element is satisfying and gratifying user. On the other hand, every organization in order to reach customer needs should engage with customer requirement.

\section{Literature review}

Quality management, lean and Six Sigma continue to spread-out tremendously in the manufacturing sector and other sectors. These practices have progressively started their way into the construction industry (Dahlgaard \& Dahlgaard-Park, 2006; Aberdeen Group 2005; Salem et al., 2005; Abdul-Aziz, 2002; Mathews et al., 2000). Quality has applied in the construction industries because as in any other industry, "it is critical that client satisfaction is achieved if an organization is to succeed, or indeed survive" (Barratt, 2000). It is also as an industry that is characterized by a "confrontational and adversarial atmosphere with time and money being the prime concerns" (Abdul-Aziz, 2002). According to (Mane \& Patil 2015) the quality is one of the critical factors in the success of a construction project. The construction insight, the quality is to meet the client's need as per contract standard (Gibson \& Hamilton, 1994). As stated by (Jha and Iyer, 2006) that the quality of construction is starting with an approach customer expectation and satisfaction. Therefore, the quality of construction fairly related to meet the needs of each party involved in the construction project, for instance, consultants, clients, and contractors (Arditi et al., 2015).

Basically, there are different environments in project field, for example communication among project shareholders, in order to reduce the risk and improve the quality (Edmondson and Lei 2014). The environment of work in construction is dynamic and unique within workforce. Moreover, the project as limited with time, the quality and safety need to be examining to avoid any violation. Furthermore, management of construction companies is always in a dilemma, on the optimal decision, in order to attain the maximum outcome, in regard to cost and to achieve the required operational performance. There must be several plans, in order to improve the project quality and safety, such as non-conformances to record poor quality image and poor project management (Love et al., 2015). Therefore, the author considers it relevant to study in more detail, the casual process that links QMPs with quality performance. Thus, with this study, it will be possible to have the perspective result. However, previous researchers recognize the need for further testing, observing that recent studies argue, that it is important to retest the relationship between quality and performance because past studies have obtained mixed results (Naor et al., 2008). Hence, delays in project completion and poor performance in the construction industry has been experienced and led failure of achieving an effective time and cost performance (Rahman et al., 2012). Therefore, the major causes of failures are insufficient implementing capacity, poor optimization practices, weak project designs and project part interference and all that will negatively affect the operational performance. Similarly, construction project is the product of the construction industry and therefore, project performance which falls in one of the non-financial categories (product performance) defined by Gunday et al. (2011) suggested them as suitable dimensions for the performance indicator for construction industries, determining the overall organizational performance. The growing competition forces 
construction organizations to rethink their construction for improving productivity, quality, and efficiency (Karna and Jonnonen, 2005).

\subsection{Quality management practices}

Total Quality Management (TQM) is generally described as a collective, interlinked system of quality management practices (QMPs) that is associated with organizational performance (GAO, 1991; Tornow \& Wiley, 1991; Waldman, 1994; Madu et al., 1995). TQM has probably been the most significant approach to manage operations improvement. It is also seen as an approach to the way operations and processes should be managed and, more significantly, improved generally. A grasp of quality management principles is the foundation of any improvement activity (Slack et al., 2007). The concept of total quality management (TQM) has been developed as a result of intense global competition. Organizations with international trade and global competition have paid considerable attention to TQM philosophies, procedures, tools and techniques (Zakuan et al., 2010). Actually, many companies are implementing the TQM approach and quality initiatives for achieving sustainable competitive advantage and enhanced company performance (Talib et al., 2010). In fact, numerous studies have examined the positive and negative (or non-significant) relationships or correlations between TQM practices and various performance measures.

TQM has been practiced in developed countries specifically, in the UK, the USA, Japan etc. On the other hand, Total Quality Management is still new in some countries. The core objective of TQM is to improve efficiency among employees and keep improving competitiveness in the international marketplace (Agus \& Abdullah, 2000). Quality management practices (QMPs) have been investigated extensively (Saraph et al., 1989; Flynn et al., 1994; Waldman, 1994; Powell, 1995; Ahire et al., 1996; Anderson \& Sohal, 1999; Najmi \& Kehoe, 2000; Zhang et al., 2000; Sun, 2001; Sila \& Ebrahimpour, 2002; Kaynak, 2003). Numerous studies have examined the positive and negative (or non-significant) relationships between QMPs and various performance measures. While examining the relationship between QMPs and performance scholars have used different performance types such as financial, innovative, operational and quality performance. Another author measured organizational performance for quality performance (example quality of product and service, customer relations, customer satisfaction with product quality, and level of quality performance relative to industry norms) (Arumugam et al., 2008). Brah et al. (2000) determined how an organization could benefit from QMPs implementation in terms of improved financial performance. Several authors have specified that the best management must establish quality management for improvement (Parast et al., 2011). The top management clarifies the inconsistency of operational execution of the organization. Pioneers are playing a basic part as drivers of TQM in term of improving the TQM elements (Tari et al., 2007).

Therefore, applying QM practices has been taken as the concentrated of the quality management, social backbone of quality administration (Rad, 2006). Documentation of the quality data/information should be applied in the project accordingly the remedied activities can be taken in a proper manner (Flynn et al., 1995; Kaynak, 2003). These are measures, the degree of change in operational performance of the construction industry, it is indicated in the below points according to Quality management practices elements (adapted from Patyal \& Koilakuntla 2015).

1) Top Management: Management leadership and commitment are required for TQM implementation. Good and effective leadership generally denotes keeping a close involvement in the implementation activities for the purpose of maintaining the momentum of the employees towards customer satisfaction (Negri, 2003). Specifically, QMPs such as: management, leadership, process management, employee involvement and customer focus are commonly accepted practices to improve quality performance of companies (Zehir et al., 2012).

2) Employee involvement: Employee involvement is important due to the fact that lack of it has been found to be a barrier to the successful implementation. In other words, human resource has a crucial role in the implementation process as the middle managers and the employees need to be motivated, trained and involved in an in-depth manner. (Kanji and Wallace, 2000). Employee associations indicate, the degree of which workers are including the quality endeavors and take an interest in quality adoptions and they have commitments to supply qualified workers and product moreover they need to remedy the quality issues (Saraph et al., 1989). 
3) Supplier Involvement: Supplier quality management is as the materials and the purchased part is sometimes the root of quality problems (Zhang et al., 2000). Alternatively, poor quality of supplier products generally leads to extra costs for the purchases. This explains why a major portion of quality problems can be rooted in the supplier.

4) Customer involvement: Generally speaking, customers are often considered as an asset of the economy. Although, they are not listed on the balance sheet, several studies suggest that they should be (Kanji \& Wallace, 2000). Al-Zoubi (2012) stated that, encourage the employees apply their technical and management perspective and innovative idea in order to meet customer requirement and also to achieve the quality standard. Agus \& Noor (2010) pointed that demand anticipation is one of the contributor that helps the organization to minimize operational costs, increased efficiency and on time delivery of goods and services.

5) Education and Training: Ahire et al. (1996) stipulated the importance of training and development by stating that employee empowerment and involvement framework will not be effective until and unless employees become recipients of formal, systematic training in quality management. In terms of Human Resource. Abdul Raza (2010) stated that training the workers can improve the operational performance in local and international markets. Training of the existing construction industry workforce, the industry has to overcome shortages of technical, managerial, skilled and unskilled personnel. The construction industry human resources are the key challenge that has a significant portion to fulfill construction demand. Identically, (Barker and Emery, 2006) noticed that the training give to employees need to be continued to cover the quality control and to provide an appropriate solution for any problem that can be evaluated at early stage during the execution the project.

6) Information and Analysis: construction industry is fragmented in nature both geographically and functionally (Aziz \& Salleh, 2011), difficulties in managing human resources as well as implementation of technologies in the industry are inevitable Information and Analysis is concerned with the evaluation of different policies and strategies, quality audit, quality costs, evaluation of department/functional performance, and evaluation of employee-supplier performance. If the dissemination of the product information is inferior, quality techniques such as benchmarking and statistical process control (SPC) tools will not work. Sanchez-Rodriguez et al., (2006) provided the insights into the current information technology (IT) and quality management (QM) theory and practice of operational and quality performance. They found QMPs initiatives generate significant positive gains in operational and quality performance. Technology and capital-intensive construction are other challenging areas of the industry and these will reduce reliance on labour or human capital. The use of mechanisation, pre-fabrication, IT and creative use of new construction project management techniques is vital to boost the industry's capabilities and performance.

Decreasing cost of construction, improvement in service delivery quality, growing capacity of government, improving decision making process, and transparency, increasing efficiency and immediate access to pertinent information, are among the benefits of IT application in construction industry (Aziz \& Salleh, 2011).

7) Continuous Improvement: Continuous improvement implementation of the management of everyday activities is imperative for the employees working towards the success of the organization. The industry needs to prepare for paradigm shifts to improve its competitiveness that can be achieved by using best practices, advanced construction techniques and optimize resources utilization. Increasing productivity is the greatest untapped area for improvement in the construction industry.

8) Process Management: Process management is considered as the concern of conformance quality. One important element of process management is to guarantee that process capability is able to achieve the production requirements (Zhang et al., 2000). Human capital is considered a valuable resource that is inimitable, which allows the organization to sustain their competitive advantage (Chowdhury et al., 2014). On the other hand, Ekstrom \& Bjornsson (2004) stated that reengineering of procurement processes together with investments in IT could lead to improved productivity. Lee \& Ooi (2014) stated that to improve and maintain the quality of work that required proper selection of skillful workforce. 


\subsection{Leadership}

Generally, Leadership provides a good work environment for empowerment, innovation, improvement and striving to increase the performance, the communication among project parties (Flynn \& Saladin, 2006). Moreover, a study by Turner (2014) quoted that active leadership can lead the management to the successful way since they used a proper technique. The roles and accountability of project manager towards the project team and project stakeholders is to keep progressing the project outcome (Fung \& Ramasamy, 2015; Jiang, 2014), specified that the leaderships can directly add a good expectation into the project performance on the other hand, they can indirectly affect the project success through teamwork development. On the contrary, Anantatmula (2010) and Fung \& Ramasamy (2015) argued that the leadership does not directly affect the project success because the roles of leadership are depending on various factors which contribute to improve the project performance. Alotaibi et al. (2013) noticed that the TQM need to be established on tradition, beliefs, and cultures as designed in TQM strategies. Therefore, active leadership of the project needs to perform the work to mitigate the errors Love \& Smith (2016) Green (2012) and Sweis et al. (2013) stated that the need for leadership must encourage the employees to use the management thinking and creative thinking during the work. According to (Kaynak, 2003, Vishal, 2016) top management must locate the proper resources to put their efforts in process product design process practices. (Flynn et al., 1995; Ahire \& Ravichandran, 2001; Kaynak, 2003) cited that leadership, top management commitment, involvement, recognition, reward, education have a direct and indirect effect on employee's satisfaction. Shan et al. (2013) highlighted that, the organization needs to establish very strong link with client and periodically discuss their opinions and always correspondingly need to understand the future expectation, if the client needs to change the project requirement. Similarly, Mohammad (2016) stated that leadership is under his accountability to select a convenient employees and supplier to match the client requirement and expectations. Kaynak (2003) said that the leadership should make a proper correlation with a supplier and get proper feedback about the supplied product and the quality during producing the product.

Veeri \& Arumugam (2008) noticed that the leadership has an important part to continual improvement practice in ISO 9001 accredited organizations. The effective management and leadership of the project team are to perform work in an exempted manner and mitigated errors during the procurement of the project (Love \& Smith 2016). The significance of leadership to construction project success is as follows:

1. Ensure that the project is monitored and constructed smoothly (Senam ,2014)

2. Understand that the conflicting idea is to enhance organizational success (Udhayakumar, 2014)

3. Increase the organization's profitability (Russell, 2004),

4. Encourage continuous skills to convey the nonprofessional leader to professional (Udhayakumar, 2014).

\subsection{Quality culture in construction industries}

Culture can define itself in the form of declared practices and values. Its principle is a comprehensible set of beliefs, which influence the way of performing. Commonly quality culture starts with leadership that understands and believes the implication of the system view and knows the necessity of serving customer in order to succeed (El Safty, 2012). According to (Keng et al., 2016) the organization needs to provide particular training for all employees willing to adopt a new culture in order to impose quality culture within the organization and to be practiced by all employees and site workers. Hence, a large construction company must combine and balance the strategic objectives of the company, a strategic perspective, with local market conditions and operative thinking, an operational perspective (Peter, 2006). Moreover, he noticed that the foundation of any quality improvement is to develop a quality culture or mind-set within the organization and integrate it throughout the organization. Quality culture has very close dependency relationship with customer relationship. So, several researchers verified that quality management needs an organizational culture of commitment to customer satisfaction through continuous improvement (Penland, 1997; Manley et al., 1998; Alotaibi et al., 2013).

In terms of construction industries, it is often criticized for its poor performance on quality, cost, safety and speed, there are various reasons for the criticism. Initial construction industries contain of 
several parties, each of them have their contribution to ensure the quality of the product and service. Nevertheless, the poor performance of one party may affect the performance of the other party. Hence, the production processes in the construction industry are to some extent different for each project. Furthermore, excessive changes to the details of the design of a project are typical throughout the construction process. All that will lead to disputes and confrontational relations among the parties may cause project performance in risk. Having in place an error prevention culture can positively engage the psychological safety in construction projects, which lead to study and learn from the errors that happened during executing the work (Love et al., 2019). Moreover, company highlights the need of creating quality culture in construction to ensure continued quality performance. The cultural awareness of quality, its importance to the business and its customer's must be led and supported by senior management who also has the duty to set an environment, which fosters a customer oriented culture and the importance of quality in everyday business operations.

A company culture which, has a big focus on quality, can be attained through active engagement with customers and their needs, tracking quality performance not only through the sales and marketing department but also throughout all levels of the organization. Activities and initiatives that can enhance the quality culture of organization's employees are listed below:

1) Regular customer visits to the company's operations including site tours, product presentations, and meeting staff at all levels.

2) Regular visits of not only sales representatives, but also managers and staff to customer plants, job sites or operations in order to understand their operations and uses for the products and services they buy.

3) Continuous improvement initiatives and programs relating to product and service quality.

4) Education and continuous upgrading of the workforce in quality standards, customer requirements and industry best practices.

5) Management support from all levels for the pursuit of quality, continuous improvement, and customer satisfaction.

\subsection{Operational performance}

Performance measurement is very important indicator, which measures the organization problem. Operational performance (OP) is defined as the actual outcome that is measured by the indicators of quality improvement, efficiency/effectiveness, cost reduction, client unwaveringness and on-time delivery of inventory to the organization (Iyer, 2011). According to (Ahmad \& Schroeder, 2003) the Operational Performance is the most common indicator for measuring operational element that includes cost, quality, delivery, and flexibility. Operational execution is required to boost an organization's competitive edge through improvement of value, cost reduction quality, persistence, time to market, and item development, client lead times, stock levels, and conveyance time (Ngatia, 2013). Indicators of effective operational performance include: enhanced financial performance, lead time performance, enhanced responsiveness, client unwaveringness, advancement, quality items, and decrease in abundance stock levels and upgrades in item/prepare outline (Croom \& Johnson, 2003). Normally if the material is not managed properly, it will affect the cost in construction projects (Lenin et al., 2016). Inefficiency in operational performance is likely to rise when material is not tracked properly in order to optimize on cost.

On the other hand, there are researches that measure the performance by several elements such as market, financial, business innovation and organizational performances. According to Harbour (2009) stated that the performance is executing and instigating a set of activities and these activities indicate actual outcome. The definition of performance is the achievement of the organizational performances or organizational goals. Richard et al. (2009) stated that the organizational performance is a vital construct to achieve the objective of the organization activates. Similarly, operational performance is intently viewed from the financial perspective which gives consideration to effects sales volume, budgets, revenues growth (Liao \& Wu, 2009). Alternatively, Vague and undocumented coordination among project contractors, consultant, client and supplier in Supplier channel system can lead to many negative consequences, such as higher inventory costs, longer delivery times, higher transportation costs, poor customer service, higher levels of loss and damages, and consequently, a greater environmental impact (Simatupang, 2005). A study 
has been done in Malaysia to improve operational performance in construction industry and the author found that the focus on health, safety and environment at construction sites. Further, training of the existing construction industry workforce, the industry has to overcome shortages of technical, managerial, skilled and unskilled personnel. The construction industry's human resources are the key personal that has a significance influence on the industry demand.

A limited study has conducted between the relation of TQM and operational performance especially in the construction industry, such as (Kuo \& Kuo 2010); Ali \& Rahmat (2010), Din et al., (2011), Mir \& Pinnington (2014) and Leong et al. (2014). Kuo \& Kuo (2010) considered the link between TQM and project performance in Taiwan using structural equation modelling (SEM) and they found that the TQM elements have a direct effect on project performance. Moreover, a study conducted by Ali and Rahmat (2010) scrutinized the performance measurements of construction projects managed by ISO-certified construction industries in Malaysia and he found that The functionality of TQM and clients' satisfaction were very powerful elements for measuring construction project performance otherwise the project time delivery and cost which are the less important. Mir \& Pinnington (2014) found that the positive relation between TQM and the success rate of a project in the UAE. Leong et al. (2014) measured the performance level of implemented ISO 9000 certification in Malaysia industries by implementing KPI in the project and the study result was the time variance and customer satisfaction were completely affected by ISO 9000 certification.

In terms of the leadership, which empowers the communication among the employees and supplier? Study carried out by Arshinder et al. (2008) proposed that coordinated procurement process enhances the firms' performance by integrating the coordination and communication mechanism in the traditional procurement process and other study done by (Mwangi, 2016) on the factors influencing performance of contractors in the road construction sector in Kenya and he found out that working capital, skilled manpower, organization structure and client contributed high rate among the factors influencing performance of road contractors in Kenya. The relationships of internal resources (human success factor and information technology) and procurement process coordination on operational performance. Valmohammadi \& Roshanzamir (2015) stated that workforce oriented activities increase the organizational performance. Most studies mentioned that the workforce focus has very important link to the organization performance. The organization must specify factors that are critical for the organization to succeed, leading to the term 'success factor' in prior literature (Aziz \& Salleh, 2014). The direct effect of human with strong skills and motivation is that they tend to work faster and smarter, which consequently leads to better performance (Kehoe \& Wright, 2010; Mahsud et al., 2011). One study prepared in Spain indicated that the workforce was a dynamic element to increase the achievement of service industries (Psomas et al., 2014). Therefore, employee involvement (EI) practices clearly an underlying factor in the recent transformation in operational effectiveness among US manufacturers (Ettlie, 1988; Gordon, 1992; Hoerr \& Zellner, 1989; Womack et al., 1990). Mark, (2000) Operational improvements have been pursued through techniques such as just-in-time manufacturing, total quality management, concurrent engineering and employee involvement.

Contractors are increasingly becoming more dependent on suppliers to complete projects while striving for the required performance in these projects (Bemelmans, 2012). Even though, there are many evidence that show benefits that industries such as manufacturing and retailing had gained from effectively managing supply chain coordination, there is however limited evidence of its success and its impact in construction industry (Othman, 2011). Furthermore, Lenin et al. (2014) carried out a study on improper material management affecting cost in construction projects in India and his study Findings revealed that the top five major causes of cost overruns were design issues, market condition, store issues, contractor issues, and external issues. Their Recommendations were given for reducing material mismanagement in the construction industry thus leaving behind the effects of material mismanagement and the industry need to obtain a great operational performance, avoid waste and select proper resources. The customer/client, this concept was studied by Zou et al. (2014) and they found an active customer relationship management strategy leads to better project performance, but the relationship keep changing across project stages. Psomas et al. (2014) revealed that the customer focus policy was the key of TQM factor, which positively affect service sector (Sabella et al., 2014). 
Due to the fragmented nature of the construction industry, coordination is important in dealing with the interdependencies and complexities of activities and processes (Othman, 2011). In terms of using the technology and process management, the use of technology has the capability to provide operational benefits, such as reduction in cost and improvement in services, and strategic benefits, such as improvements in product planning and innovation (Prajogo \& Sohal, 2013; Chien \& Barthorpe, 2010; Davies, 2008; Love \& Irani, 2010; Tse \& Choy, 2005). Construction processes should be taken into account together with other factors such as people, procurement, legal issues, and knowledge management for successful application of IT (Kang et al., 2013). Bouranta et al. (2017) stated that the concern about the validity and reliability of information and data used in industries need to be used in proper way and need to be analysed and measured to support quality-based and decision-making all that to improve the performance of a project. Hralian et al. (2017) and Valmohammadi \& Roshanzamir (2015) suggested the implementation of data collection and an analysis system can directly effect to improve the performances of industries. Zeng et al. (2015) conducted the study for 283 manufacturers and they observed that the quality information had a direct impact on quality performance in ASIAN countries. Irfan \& Kee (2013) and Agus (2011) stated that the quality information and analysis have had a substantial channel on performance. The empirical study done by Mehralian et al. (2017) mentioned a proper relationship between process management and performance. Valmohammadi \& Roshanzamir (2015), Zeng et al., (2015); Irfan \& Kee (2013) and Zehir et al. (2012) all of them have the same feedback regarding the positive correlation between process management and performance. On the contrary, (Talib et al., 2013) stated that in a study which was conducted in India on 172 service industries and finding the process management didn't affect the quality performance. As Deming's believe, improving the process management can improve the quality in order to achieve high performance of the project (Shieh \& Wu, 2002).

\section{Theoretical framework}

Several empirical types of research on quality management practices propose that the researchers have defined quality management practices elements in various concepts even though the construct is similar to each other. In this research, the author used some of the elements which affect the operational performance with help of leadership and quality culture to assist the awareness of the employee about the quality of the project. The relations proposed in the study framework (Figure 1) have explained from studies in the literature on leadership, quality culture, quality management practice and operational performance. Therefore, based on the analysis of previous studies, the purpose of this study is to provide a proper framework that links all the variables in construction project.

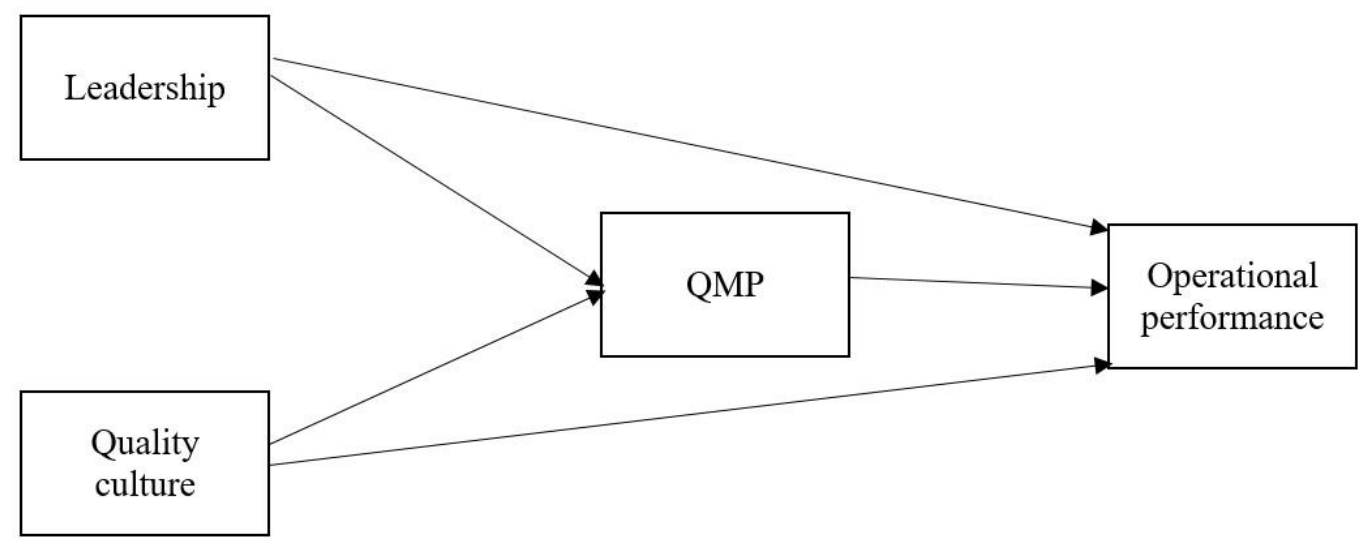

Figure 1. Hypothesized path model

Source: Author (2020)

\section{Conclusions}

This paper solely focused in providing a conceptual analysis of QMP interaction. Based on the discussion on the introduction, literature review the QMP gives the impression to be important in construction industries particularly with control of leadership and impose the quality culture to improve the 
operational performance. The review of literature and the previous studies show that it is essential to expand the learning to introduce reasonable information. The contribution of this study is to present a new hypothesis to explain the relative variable above this study. A study support on quantitative analysis to validate the proposed model is recommended.

\section{Acknowledgement}

In preparing this thesis, I was in contact with many people, researchers, academicians, and practitioners. They have contributed towards my understanding and thoughts. In particular, I wish to express my sincere appreciation to my paper reviewers.

\section{References}

1. Agus, A., \& Noor, Z. (2010). Supply Chain Management and Performance: An Empirical Study, University of Malaysia. Singapore.

2. Alotaibi, F., Yusoff, R. Z., \& Islam, R. (2013). Assessing the impact of total quality management practices and quality culture with competitiveness of Saudi contractors. American Journal of Applied Sciences, 10(6), 638-645. https://doi.org/10.3844/ajassp.2013.638.645

3. Al-Zoubi, M. T. (2012). Generating benchmarking indicators for employee job satisfaction. Total Quality Management and Business Excellence, 23(1), 27-44. https://doi.org/10.1080/14783363. 2011.637780

4. Arditi, D., Arditi, D., \& Gunaydin, H. M. (2015). Total quality management in the construction process Total quality management in the construction process. International Journal of Project Management, 7863(AUGUST 1997), 235-243. https://doi.org/10.1016/S0263-7863(96)00076-2

5. Barrett, P. (2000). Systems and relationships for construction quality. International Journal of Quality and Reliability Management, 17(4), 377-392. https://doi.org/10.1108/02656710010298409

6. Croom, S., \& Johnston, R. (2003). E-service: enhancing internal customer service through e-procurement. International Journal of Service Industry Management, 14(5), 539-555

7. Dahlgaard, J. J., \& Dahlgaard-Park, S. M. (2006). Lean production, six sigma quality, TQM and company culture. TQM Magazine, 18(3), 263-281. https://doi.org/10.1108/09544780610659998

8. Edmondson, A. C., \& Lei, Z. (2014). Psychological Safety: The History, Renaissance, and Future of an Interpersonal Construct. Annual Review of Organizational Psychology and Organizational Behavior, 1(1), 23-43. https://doi.org/10.1146/annurev-orgpsych-031413-091305

9. Flynn, B. B., \& Saladin, B. (2006). Relevance of Baldrige constructs in an international context: A study of national culture. Journal of Operations Management, 24(5), 583-603. https://doi.org/10.1016/j. jom.2005.09.002

10. Gunday, G., Ulusoy, G., Kilic, L., \& Alpkan, L. (2011). Effects of Innovation Types on Firm Performance. International Journal of Production Economics, 133(2), 662676.

11. Irfan, S. M., \& Kee, D. M. H. (2013). Critical success factors of TQM and its impact on increased service quality: A case from service sector of Pakistan. Middle East Journal of Scientific Research, 15(1), 6174. https://doi.org/10.5829/idosi.mejsr.2013.15.1.828

12. Iyer, K. N. S. (2011). Demand chain collaboration and operational performance: role of IT analytic capability and environmental uncertainty. Journal of Business \& Industrial Marketing, 26(2), 81-91. https://doi.org/10.1108/08858621111112267

13. Juran, J. (1982). Juran on quality improvement. New York; Juran Institute.

14. Juran, J., \& Gryna, M. (1993). Quality planning and analysis, New Delhi; Tata McGraw-Hill.

15. Kanji, G. K., \& Wallace, W. (2000). Business excellence through customer satisfaction. Total Quality Management, 11(7), 979-998. https://doi.org/10.1080/09544120050135515

16. Kaynak, H. (2003). The relationship between total quality management practices and their effects on firm performance, Journal of Operations Management. 21(4), 405-435.

17. Kehoe, R. R., \& Wright, P. M. (2013). The Impact of High-Performance Human Resource Practices on Employees' Attitudes and Behaviors. Journal of Management, 39(2), 366-391. https://doi.org/10.1177/ 0149206310365901 
18. Keng, T. C. (2016). Implementation of ISO Quality Management System in Construction Companies of Malaysia. Journal of Technology Management and Business, 3(1).

19. Lenin, P., Krishnaraj, L., Prasad, D. N., \& Kumar, V. R. P. (2014). Analysis of Improper Material Management Affecting Cost in Construction Projects. International Journal for Research in Applied Science and Engineering Technology Analysis.

20. Love, P. E. D., \& Smith, J. (2016). Toward Error Management in Construction: Moving beyond a Zero Vision. Journal of Construction Engineering and Management, 142(11), 04016058. https://doi.org/10.1061/(asce)co.1943-7862.0001170

21. Love, P. E. D., Smith, J., Ackermann, F., \& Irani, Z. (2019). Making sense of rework and its unintended consequence in projects: The emergence of uncomfortable knowledge. International Journal of Project Management, 37(3), 501-516. https://doi.org/10.1016/j.ijproman.2019.02.004

22. Love, P. E. D., Teo, P., Carey, B., Sing, C. P., and Ackermann, F. (2015). "The symbiotic nature of safety and quality in construction: Incidents and rework non-conformances."Safety Science 79: 55-62.

23. Naor, M., Goldstein, S. M., Linderman, K. W., \& Schroeder, R. G. (2008). The Role of Culture as Driver of Quality Management and Performance: Infrastructure versus Core Quality Practices*. Decision Sciences, 39(4), 671-702. https://doi.org/10.1111/j.1540-5915.2008.00208.x

24. Ngatia, C. W. (2013). Supply Chain Management Practices and Performance of Kenya Tea Development Agency Managed Factories. Journal of International Business Studies, 2(2), 64-69.

25. Psomas, E. L., Pantouvakis, A., \& Kafetzopoulos, D. P. (2013). The impact of ISO 9001 effectiveness on the performance of service companies. Managing Service Quality, 23(2), 149-164. https://doi.org/10.1108/09604521311303426

26. Psomas, E., Vouzas, F., \& Kafetzopoulos, D. (2014). Quality management benefits through the "soft" and "hard" aspect of TQM in food companies. TQM Journal, 26(5), 431-444. https://doi.org/ 10.1108/TQM-02-2013-0017

27. Rad, A. M. M. (2006). The impact of organizational culture on the successful implementation of total quality management. TQM Magazine, 18(6), 606-625. https://doi.org/10.1108/09544780610707101

28. Rahman, I. A., Memon, A. H., Nagapan, S., Latif, Q. B. A. I., \& Azis, A. A. A. (2012). Time and cost performance of costruction projects in southern and cenrtal regions of penisular Malaysia. CHUSER 2012 2012 IEEE Colloquium on Humanities, Science and Engineering Research, (March), 52-57. https://doi.org/ 10.1109/ CHUSER.2012.6504280

29. Samarghandi, H., Tabatabaei, S. M. M., Taabayan, P., Hashemi, A. M., \& Willoughby, K. (2016). Studying the reasons for delay and cost overrun in construction projects: The case of Iran. Journal of Construction in Developing Countries, 21(1), 51-84. https://doi.org/10.21315/jcdc2016.21.1.4

30. Saraph, J., Benson, P., \& Schroeder, R. (1989). "An instrument for measuring the critical factors of quality management", Decision Sciences. 20(4), 810-892.

31. Senam, M., Rashid, K., Sarkawi, A., \& Zaini, R. (2014). Construction project leadership from the perspective of Islam, International Journal of Islamic Thought, 6, 46-56.

32. Senge, \& Peter. (2006). The Fifth Discipline: The Art and Practice of the Learning Organization, $\{$ ISBN\} 0385517254, 9780385517256, Doubleday/Currency, New York. NY.

33. Shah, R., \& Ward, P. (2003). Lean manufacturing: Context, practice bundles, and performance. Journal of Operations Management, 21(2).

34. Sweis, R. J., Al-Mansour, A., Tarawneh, M., \& Al-Dweik, G. (2013). The impact of total quality management practices on employee empowerment in the healthcare sector in Saudi Arabia: A study of King Khalid Hospital. International Journal of Productivity and Quality Management, 12(3), 271-286. https://doi.org/10.1504/IJPQM.2013.056149

35. Wachuma, P., \& Shalle, N. (2016). Effect of Lean Supply Chain Management Practices on Organizational Performance in Government Ministries in Kenya: A Case of Children's Department in the MLSSS. International Journal of Academic Research in Business and Social Sciences, 6(5), 364-375. https://doi.org/10.6007/ijarbss/v6-i5/2154

36. Waldman, D. A. (1994). The Contributions of Total Quality Management to a Theory of Work Performance. Academy of Management Review, 19(3), 510-536. https://doi.org/10.5465/amr. 1994.9412271811 
37. Zaini, B. (2000). Malaysian construction industry: challenges and demands. Annual Convention of Malaysian Structural Steel Associatio, 11(7), 979-998. https://doi.org/10.1080/09544120050135515

38. Zakuan, N. M., Yusof, S. M., Laosirihongthong, T., \& Shaharoun, A. M. (2010). Proposed Relationship of TQM and Organisational Performance using Structured Equation modelling. Total Quality Management \& Business Excellence, 21(2), 185-203.

39. Zehir, C., Ertosun, Ö. G., Zehir, S., \& Müceldilli, B. (2012). Total Quality Management Practices' Effects on Quality Performance and Innovative Performance. Procedia - Social and Behavioral Sciences, 41, 273-280. https://doi.org/10.1016/j.sbspro.2012.04.031.

40. Zhang, Z. (2000). Implementation of total quality management: An empirical study of Chinese manufacturing firms. Unpublished Doctoral thesis, University of Groningen, Groningen, The Netherlands. 1(3), 375-390. https://doi.org/10.1080/09544129000000046. 